Revista Iberoamericana, Vol. LXXV, Núm. 228, Julio-Septiembre 2009, 819-839

\title{
HACIA UNA POÉTICA DEL NAUFRAGIO: MELANCOLIIA Y ESTUDIOS TRANSATLÁNTICOS
}

\author{
POR \\ Tabea Alexa Linhard \\ Washington University in St. Louis
}

Está distante el mar, y sin embargo, nos rodea más
y más.
Cristina Peri Rossi, Descripción de un naufragio
En el mar no aparecen las historias, sino en el pico
de las olas desaparecidas. Donde nada es asible.
Angelina Muñiz-Huberman, Castillos en la
tierra

En los últimos años los estudios transatlánticos han cuestionado y cruzado fronteras disciplinarias y genéricas; de manera paralela, el origen mismo de dichos estudios está en las múltiples travesías que unieron diferentes puntos geográficos que comparten el acceso al océano Atlántico. En el presente artículo propongo una revisión de los estudios transatlánticos partiendo del tropo de la travesía marítima y de sus consecuencias discursivas. Concretamente, se trata de analizar los estudios transatlánticos a partir de una "poética del naufragio", es decir de la articulación de un estado melancólico producido por pérdidas irreparables que surgen con las travesías marítimas entre las Américas, Europa y África. Tales extravíos los constituyen elementos irrecuperables e innombrables (seres amados, ideales, hogares, memorias) que permanecerán excluidos de aquellas comunidades que acogen, ya sea de manera hospitalaria o no, tanto a las viajeras y viajeros como a los conceptos, ideas y formaciones discursivas que cruzaron, cruzan y cruzarán el océano Atlántico.

El mar que aparece en los epígrafes de este ensayo también es el mismo mar por el que navegan barcos llenos de horas robadas por dudosos tiempo-traficantes: éste es el mar que atraviesan las niñas Alicia y Alberina, protagonistas respectivas del relato “La influencia de Edgar A. Poe en la poesía de Raimundo Arias” de la uruguaya Cristina Peri Rossi y de la novela Castillos en la tierra de la hispanomexicana Angelina Muñiz-Huberman. Aunque las jóvenes protagonistas de las dos obras 
cruzan este mar de oeste a este y de este a oeste por barco, y llegan relativamente sanas y salvas a sus respectivos destinos, ambos textos también son, para citar otro título de Peri Rossi, la “descripción de un naufragio”. ${ }^{1}$ En el cuento de Peri Rossi y en la novela de Muñiz-Huberman se narran el exilio durante la dictadura uruguaya y el exilio republicano en México respectivamente, pero lo que verdaderamente los une entre sí -y a la vez con las posibilidades teóricas de los estudios transatlánticos en relación a Latinoamérica- es la articulación de una pérdida irrecuperable.

Dicha pérdida se traduce en un estado melancólico que, más que crear una parálisis teórica, posibilita un nexo entre los exilios que marcarían profundamente el desarrollo de la literatura en el mundo hispano durante la segunda parte del siglo xx y los más recientes flujos de capitales, de personas e incluso de estupefacientes. ${ }^{3}$ Esta

1 Me refiero al poemario Descripción de un naufragio, publicado tres años después de que la autora iniciara su exilio en Barcelona. El primer epígrafe también pertenece a dicho poemario (14). En adelante todas las traducciones del inglés al español son mías.

2 A pesar de que ambos textos pertenezcan a contextos muy diferentes, las historias de Alicia y Alberina coinciden en los sacrificios que implica su travesía transatlántica. El hecho de que el exilio que ambas autoras narran a lo largo de sus respectivas extensas obras se relacione con lo irrecuperable no es, por supuesto, novedad alguna, y en este artículo no se propondrá otra articulación teórica sobre el exilio y sus consecuencias discursivas. Es una investigación que más recientemente ha sido llevada a cabo por Baumgartner y Pfeiffer (2005), Faber (2003), Kaminsky (1999) y McClennen (2004). A la vez, este artículo no es un examen riguroso de las particularidades de los dos respectivos exilios aquí tratados, el uruguayo y el español; tanto más información como diferentes perspectivas sobre los mismos se pueden encontrar por ejemplo en las colecciones de ensayos de Sosnowski (1987) y Naharro-Calderón (1991). Cabe contrastar aquí las palabras de dos autores incluidos en las mismas, que otra vez muestran la fractura irreparable que implican estos dos exilios a pesar de sus múltiples diferencias, tantas que una mera lista sólo las trivializaría. Hugo Achugar señala en referencia al exilio uruguayo: “Marginalidad, extranjería, 'ser entre dos aguas' apuntan a una definición del espacio; apuntan a no estar o al estar fuera de sitio o al estar fuera de pertenencia. Pero también a un fenómeno que es del Uruguay todo y no sólo de los desexiliados; marginalidad o separación, fractura de un cuerpo social que busca dificultosamente una organicidad desgarrada por la experiencia de la dictadura” (Achugar 242, énfasis mío). Por su parte, Sánchez Romeralo invoca las palabras del español Juan Ramón Jiménez, que también desde el exilio había expresado: "Para el desterrado, la tierra mejor, el terreno único de su patria es el mar (terreno, digo, porque el mar tiene fondo y puede uno ser enterrado en él), patria universal” (256).

3 En su introducción al número especial dedicado al Atlántico hispano de la revista Arizona Journal of Hispanic Cultural Studies, Joseba Gabilondo relaciona dichos flujos con la necesidad de reformular las posibilidades teóricas de un Atlántico hispano. Gabilondo arguye que pensar a partir de un Atlántico hispano implica una lectura nueva de la modernidad, comenzando por la colonización de las Américas; así, Gabilondo ve una continuidad entre una teorización del Atlántico y la experiencia colonial (100). A la vez, el número especial también responde a lo que Gabilondo denomina "vaivén de capital y cuerpos a través del Atlántico” (92) con fenómenos relativamente recientes como la inversión española en América Latina y la inmigración latinoamericana y africana en España. El número no incluye, sin embargo, una reflexión sobre los exilios anteriormente mencionados ni tampoco otros temas pertinentes, como por ejemplo la "narcogeografía” que ya empieza a aparecer en otros volúmenes posteriores. 
pérdida, finalmente, también se discutirá en relación a la noción de Atlántico negro (BlackAtlantic) que desarrolla Paul Gilroy. Los encuentros y desencuentros entre las Américas, África y Europa -tematizados aquí a través de dos imágenes (de Turnery Serra), un cuento (Peri Rossi) y un texto autobiográfico(Muñiz-Huberman)demandan una constante reflexión sobre las posibilidades teóricas y políticas de los estudios transatlánticos y su relación con los estudios latinoamericanos. El vínculo que une aquellos exilios que van de mediados a finales del siglo xx con los desafíos del siglo xxi justamente se halla en una poética del naufragio perfilada a través de los ya mencionados textos de Peri Rossi y Muñiz-Huberman.

Se trata de una forma de pérdida y desaparición que, al igual que comenta la niña Alberina, a primera vista aparenta ser "pura y sin huellas", pero que termina asemejándose a "una muerte repetida” (67). Así, el espacio triangular en el que se encuentran América Latina, África y Europa forma una cartografía espectral en la que las historias, las memorias y los sueños naufragados permanecen atrapados. Esta “muerte repetida”, lejana e inalcanzable, este naufragio, es también una parte constitutiva de toda travesía transatlántica relacionada con el exilio y la diáspora. A la vez, cualquier cruce teórico entre los estudios transatlánticos, los estudios latinoamericanos y también los estudios mediterráneos ${ }^{4}$ implica necesariamente el análisis del elemento melancólico, de todo lo perdido e irrecuperable. La melancolía siempre ocurre a consecuencia de una pérdida y, si bien no toda pérdida termina resultando en un estado melancólico, dicho estado sí representa las consecuencias de las travesías (y también de sus fracasos) anteriormente mencionadas.

Tanto en la noción del Atlántico negro como en el cuestionamiento de los múltiples significados del Atlántico hispano discutido por varios teóricos que trabajan dentro, a través de o a pesar de las disciplinas de los "estudios peninsulares" y “estudios latinoamericanos", las travesías -de este a oeste, de oeste a este- y las naves en los que las mismas o bien se llevan a cabo o fracasan estrepitosamente son mucho más que una mera metáfora. ${ }^{5}$ Las diversas contingencias históricas que se hallan detrás de formaciones como el Atlántico negro o el Atlántico hispano también indican que cualquier referencia a travesías, a barcos y a la siempre inminente posibilidad de naufragio es una alusión a los límites en los que las metáforas se estrellan con lo que buscan representar.

Sólo cabe tener en cuenta dos imágenes, una proveniente del contexto específico que teoriza Gilroy, y otra, mucho más reciente, fruto de los presentes flujos

4 Los estudios mediterráneos se enfocan en los constantes intercambios sociales, culturales y políticos que han marcado el desarrollo histórico de pueblos que comparten el acceso al Mediterráneo. Dicha perspectiva a la vez representa un desafío a una memoria histórica muchas veces concebida como monolítica a partir de 1492 hasta el presente.

5 Me refiero otra vez a los artículos publicados sobre el Atlántico hispano en Arizona Journal of Hispanic Cultural Studies. 
migratorios entre España y África, para enfatizar las muy reales y muy violentas circunstancias que motivan el presente análisis y que de ninguna manera se pueden trivializar como mera excusa retórica. La primera es el cuadro "The Slaveship" (1840), también conocido como "Slavers throwing overboard the Dead and Dying", del pintor inglés J. M. W. Turner, y la segunda es la fotografía "Tragedia en la costa”, tomada por Ildefonso Serra en 1992 en una playa de Tarifa. Mientras que en el cuadro se muestran los cuerpos de los muertos y moribundos, convertidos en lastre superfluo y arrojados al mar durante una tormenta, en la fotografía aparece el cuerpo de un inmigrante ahogado en su intento por cruzar el Estrecho de Gibraltar. El cuadro de Turner, tal como explica Gilroy, fue expuesto por primera vez en la Royal Academy en Londres durante una convención antiesclavista y, hoy en día, después de su propia travesía transatlántica, se encuentra en un museo en Boston (14). La fotografía de Serra fue publicada por primera vez en el periódico Europa Sur. En su análisis de dicha imagen en The Family Album, Yeon-Soo Kim explica cómo a raíz de la fotografía la escritora y periodista Nieves García Benito construye su relato "Cailcedrat". ${ }^{6}$ En el cuento, la madre del joven náufrago africano ahogado en su intento por cruzar el estrecho de Gibraltar narra la historia de su hijo; Kim sugiere que la autora deja marcadas las expresiones invisibles e inarticulables de la experiencia de la inmigración y así logra exponer la pertinencia del problema a la sociedad española en general (203).

La yuxtaposición de ambas imágenes, por lo tanto, apunta hacia la existencia de la ya mencionada cartografía espectral, en la que los múltiples naufragios fruto de las relaciones coloniales, poscoloniales y neocoloniales entre las Américas, España y África se hacen presentes. Tanto la historia del cuadro de Turner como la historia de la fotografía de Serra enfatizan el hecho de que cualquier naufragio (y también cualquier naufragio inminente) siempre es más que una metáfora. ${ }^{7}$ En el contexto del "Atlántico negro" que desarrolla Gilroy, la realidad de la violencia del tráfico de esclavos tampoco desaparece detrás de la función metafórica que adquieren los barcos de traficantes de esclavos que cruzaron el Atlántico (y aquí también se podría añadir otro tipo de naves: las fragatas de los conquistadores, las balsas, las pateras y los cayucos). En The Black Atlantic, los barcos también representan los nexos que unen diferentes puntos a ambos lados del Atlántico, son los elementos móviles que toman el lugar de los espacios que se desplazan entre los lugares fijos que conectan

\footnotetext{
6 Para un análisis de la fotografía y del relato, véase Kim 204-21.

7 Gisle Selnes menciona los riesgos que implica el análisis del naufragio en su artículo, con referencias a los destinos, muchas veces trágicos, de los que viajan en balsas o pateras: “Isn’t the juxtaposition of exile and shipwreck a reminder of the all-too-contemporary and tragic destiny of pateros (sic) and balseros who have lost their lives in an attempt to escape from a situation experienced as unlivable? This reality, one might argue, is too serious to be treated in a literary context, as a pretext for theoretico-metaphorical exercises".
} 
(Gilroy 17). Pero si los barcos son un tropo fundamental para comprender los puntos de conexión y las historias de los mismos a través del Atlántico, el siempre inminente peligro de naufragio, aludido por la yuxtaposición del cuadro de los muertos o moribundos arrojados al mar y la fotografía del inmigrante ahogado, también es parte de esta misma historia, representando el otro lado habitado por los silencios, las pérdidas irrecuperables y la consiguiente melancolía que forman, a mi juicio, una parte constitutiva de los acercamientos teóricos al Atlántico negro y al Atlántico hispano. Las historias de naufragios pasados y presentes trazan ya no una línea recta, sino más bien una estela transatlántica constituida por la re-lectura de producciones literarias latinoamericanas relacionadas con el exilio en tanto un vacío, o silencio, que convive recientemente con ruidosos y también violentos flujos de capital y de personas que siguen teniendo lugar entre las Américas, Europa y África.

Cuando Alicia y Alberina culpan al mar, a la travesía transatlántica, de robar las horas (Peri Rossi 53) y de "limpiar implacablemente, hasta que no queda nada" (Muñiz-Huberman 71), se fusionan y encuentran la historia del descubrimiento y la invención de las Américas, la historia de la colonización, también la de la Inquisición, de las construcciones nacionales y, finalmente, de los exilios del siglo xx en esta nueva cartografía espectral que, para citar a Federico García Lorca, nos remonta a aquellos "naufragios de sangre" que permanecen a veces invisibles y ocultos, a veces total y excesivamente visibles, en las historias de las relaciones transatlánticas. ${ }^{8}$ Hoy en día, cuando siguen apareciendo cuerpos muertos como el del inmigrante fotografiado por Serra y ficcionalizado por García Benito en las playas españolas (y otras del Mediterráneo), cuando las consecuencias del tráfico promovido a través de barcos como el que pintara Turner se siguen viviendo y cuando el debate sobre la memoria histórica dentro del contexto español continúa marginando el pasado colonial y sus consecuencias (y fantasmas) poscoloniales, las relaciones triangulares entre España, las Américas y África siguen afrontando un estado melancólico. Se trata, a la vez, de relaciones múltiples y superpuestas -las herencias del colonialismo español en América Latina no son equivalentes a las que se viven en el Norte de África, por ejemplo- pero que están unidas por residuos poscoloniales manifestados discursivamente en diferentes representaciones de la poética del naufragio.

\section{CRÓNICA DE UNA METÁFORA}

Se ha argüido hasta este punto que un diálogo contemporáneo entre los estudios transatlánticos y los estudios latinoamericanos se puede articular en relación con una

\footnotetext{
8 Me refiero, por supuesto, a los dos últimos versos del poema "La aurora” de Poeta en Nueva York: "Por los barrios hay gentes que vacilan insomnes/como recién salidas de un naufragio de sangre" (425).
} 
pérdida irreparable. Dicha noción de pérdida también aparece en el artículo "The Metaphoricity of Shipwrecks; or, Exile (not) Considered as One of the Fine Arts", texto en el que Gisle Selnes estudia las posibilidades metafóricas del naufragio a través de un análisis de poemas de Peri Rossi y de Borges y del relato "Los naufragios de Malinow" de Fernando Ainsa. Al discutir la relación entre el uso del naufragio como metáfora (y también los límites de este uso) en la literatura producida en el Cono Sur, Selnes sugiere que las condiciones particulares que se hallan en los orígenes históricos - “la retórica colombina de descubrimiento y apropiación”- de la producción discursiva en el dicha región implican que América Latina "provee una posición privilegiada a partir de la cual se puede pensar la condición 'universal' del desarraigo y de estar a la deriva”. Esto no supone la trivialización de la temática real del exilio, sino, tal como sugiere Selnes, que los discursos producidos en y desde América Latina sobre exilios interiores y exteriores, literales o metafóricos, necesitan formar parte de los debates, hoy en día más globalizados que globales, sobre esta misma temática, ya que tendría mucho más sentido tomar esta condición, no como un atributo esencialmente latinoamericano, "sino como la posibilidad de otorgar a una perspectiva latinoamericana cierta autoridad sobre los dilemas de los sujetos de la cultura moderna” (Selnes).

Así, la imagen recurrente del naufragio en el contexto específico de la literatura latinoamericana nos sitúa en los debates globales sobre la modernidad, y también la posmodernidad. ${ }^{9}$ Citando los estudios de Beatriz Pastor, José Rabasa y Josiah Blackmoore, Selnes explica que no es posible regresar de un naufragio: incluso si se llega a sobrevivir del desastre, el sujeto quedará marcado y transformado permanentemente. Es más, Selnes también apunta que tanto la etimología de la palabra inglesa "shipwreck" como la de la palabra "naufragio" (un naufragio es la fractura de la nave) ya implican una ruptura irreparable. Así, Selnes arguye que la etimología misma de ambas palabras -siempre se trata de la fractura de una nave, por lo tanto de un cambio- también demanda la transformación del sujeto. Selnes concluye: "El paso traumático de la estructura supuestamente segura y ordenada del barco al ámbito oscuro e inhumano del agua se hace eco en la identidad fracturada del sujeto náufrago". ${ }^{10}$

Comenzando por las diferentes formaciones discursivas de la época colonial -fundamentales, por supuesto, para comprender toda formación discursiva posterior y en especial aquellas relacionadas más directamente con las travesías hacia o desde América Latina-, el naufragio funciona como un signo (a la vez que

\footnotetext{
9 Además de los ya citados textos de Peri Rossi y Muñiz-Huberman, otras referencias obvias aquí son los Naufragios de Alvar Nuñez Cabeza de Vaca y, por supuesto, el Relato de un náufrago de Gabriel García Márquez.

${ }^{10}$ En el texto original de Selnes se lee: "The traumatic passage from the supposedly safe and ordered structure on board the ship to the dark, inhumane realm of water, echoes in the split identity of the shipwrecked subject".
} 
siempre es más que un signo) de la constante reformulación de una subjetividad que se traduce en una percepción del mundo, donde una pérdida irrecuperable siempre está en los orígenes. Ahora bien, en el resto de este artículo se trata de pensar a partir de dicha pérdida, no como algo que produce una parálisis teórica (o incluso existencial), sino como el nexo a partir del cual las relaciones triangulares que forman el Atlántico hispano ofrecen desafíos a las disciplinas y esquemas más establecidos, tal como también arguye Julio Ortega:

La lectura transatlántica parte de un mapa reconstruido entre los flujos europeos, americanos y africanos, que redefinen los monumentos de la civilización, sus instituciones modernas, así como las hermenéuticas en disputa. Por ello, esta lectura da cuenta más que de un tiempo histórico de un tiempo trans-histórico, entrecruzado de relatos una y otra vez actualizados. Su discurso se mueve entre islas que rehacen la nominación y costas que exceden la catalogación. (114)

En el contexto específico de la poética del naufragio, este "tiempo trans-histórico, entrecruzado de relatos una y otra vez actualizados" que se hace presente gracias a una perspectiva transatlántica, también es un tiempo cíclico, en el cual los fantasmas de la mencionada cartografía espectral poco a poco nos recuerdan su presencia, que permanece atrapada e incluso silenciada en el mismo mar que todo lo engulle.

BARCOS LLENOS DE HORAS ROBADAS

El mar no sólo todo lo engulle, el mar también aparece en los ojos del padre de Alicia en "La influencia de Edgar A. Poe en la poesía de Raimundo Arias”. En dicho relato, la niña Alicia se exilia junto a su padre como consecuencia de la actividad política de la madre y de un supuesto riesgo político que surge de la actividad intelectual del padre, "porque a él lo acusaron de profesar la fe marxista-leninista, y de escribir artículos que eran verdaderos panegíricos a la turba guerrillera que pretendía socavar la patria y el prestigio de las instituciones nacionales” (47). ${ }^{11} \mathrm{Se}$ podría llegar a la conclusión rápida y fácil de que el viaje de padre e hija representa la travesía de Uruguay a España, reflejando la biografía de la autora. Pero se trata de algo más complicado (y mucho más arriesgado): como ocurre a lo largo de toda la obra de Peri Rossi, los juegos retóricos y lingüísticos toman el destierro como punto de partida. En el mismo cuento aparece la temática que se retomaría en $L a$ nave de los locos, novela con la que la autora, tal como explica María Rosa Olivera-

${ }^{11}$ La figura del padre también es objeto de sátira por parte de la autora, como apunta Schmidt (223). Es más, con la investigación académica de este personaje, que otorga su título al relato, la autora satiriza el aspecto superfluo del trabajo académico en una época de revuelta política (223). 
Williams, alcanza su madurez literaria (81). Es también una novela que, al igual que este relato y la novela de Muñiz-Huberman que se discutirá a continuación, narra un viaje marítimo que siempre es más que un viaje marítimo: "El viaje, con sus coordenadas de tiempo y espacio, se convierte en un símbolo múltiple, abarcador y ambiguo”, explica Olivera-Williams, y también “da la impresión de un viaje sin desplazamiento, de un naufragio varado” (82, énfasis mío).

Los naufragios, por lo tanto, se repiten una y otra vez a lo largo de la obra de Peri Rossi y, aunque no contemos con un naufragio explícito en "La influencia de Edgar A. Poe en la poesía de Raimundo Arias”, queda claro que en este texto los personajes, tal como sugiere el análisis de Selnes, son víctimas de un naufragio: llegan a su destino, pero llegan permanentemente transformados. Alicia no sólo nunca llega a nada que se parezca al País de las Maravillas; desde el primer momento del texto, también queda establecido que con las mutaciones que implica el exilio-que igual que un naufragio conlleva una transformación permanente-los roles de padre e hija se han intercambiado. Cuando Alicia mira a su padre ve a un adulto que ha regresado a una infancia postiza: "Cuando él dejara de ser niño seguramente ya no podría ver adentro de sus ojos al hipocampo suspendido -de lenta navegación- ni la planta con flores blancas que tenía un tallo dorado” (43). También, como la cita anterior indica, ve el mar, el mismo mar que vislumbra durante su travesía rumbo al exilio. Al contemplar los ojos de su padre y ver que "[l]as aguas quietas se sacudían, corrientes interiores venidas desde lejos, desde lontananza, desde ultramar, cambiaban el ritmo y la tonalidad de los ojos” (43), se evoca el vacío que supone el exilio. Es una pérdida a la que la narradora se enfrenta con humor, pero a la vez se distancia, alejándose de la figura del padre. Esto también lo sugieren las líneas iniciales del texto, en las que se narra lo que Alicia ve en los ojos de su padre: “A ella no le gustaba asomarse a esas aguas. Veía túmulos, animales marinos, piedras, espacios refulgentes y la serena e inquietante geografía lunar” (43).

El relato, por lo tanto, apunta hacia algo más complejo que la pérdida de una identidad específica, a la que alude Cynthia Schmidt en su análisis cuando sugiere que la desorientación, la humillación y la pérdida de identidad son el resultado del desplazamiento de los personajes (223). Más bien se trata de una pérdida que nos termina remontando a aquellos naufragios anteriormente mencionados y que están ligados a los orígenes de las relaciones coloniales y poscoloniales entre América Latina y España, relaciones que por supuesto recibirán una gran carga irónica por parte de Peri Rossi en este relato.

A causa de la infantilización de un padre que en su estado de exilio no es capaz de cuidar de su hija, la niña Alicia siente la necesidad de ganar dinero y lo hace disfrazándose de "niña india latinoamericana" o "vieja enana latinoamericana" (57). Pero Alicia se viste de india no a imitación de ciertas costumbres autóctonas, 
sino siguiendo el imaginario europeo y hollywoodense sobre cómo deberían ser los indios, el único modelo a seguir disponible ya que "los españoles habían dado muerte hasta al último indio de ese país” (57). Consecuentemente, el disfraz de Alicia, más allá de ser una solución creativa y cínica a los problemas económicos de ella y su padre (Schmidt 224), no es otra cosa que la proyección (para citar a Serge Gruzinski) de un imaginario colonizado, tal como sugieren los comentarios de la niña: "Tampoco estaba segura de que se adornaran con plumas, tal como insinuaba la Metro Goldwin Mayer” (57). Así, con un tono siempre irónico, Alicia usa lo que tiene a su disposición para poder explotar y poder seguir sobreviviendo en su condición de exiliada y náufraga perpetua, lo que termina relacionando el relato de Peri Rossi con los múltiples discursos sobre la invención de América Latina. ${ }^{12}$ Y sin nunca dejar de lado la ironía que marca todo el relato, las distintas formas de violencia -epistémica, cíclica, física- que forman parte de cualquier "naufragio de sangre" se fusionan de alguna manera en el momento en que un niño nada inocente ataca a la "niña india latinoamericana” y estira "su única trenza india” (58). Alicia, por su parte, "olvidándose, de que debía murmurar sonidos ininteligibles, lo insultó en un perfecto castellano, que no tardó en adjudicar a la colonización española de las civilizaciones autóctonas del Plata” (58). El hecho de que la niña Alicia se disfrace de "vieja enana latinoamericana"-tal como lo harían muchos años después los artistas Coco Fusco y Guillermo Gómez Peña en su performance "The Year of the White Bear And Two Undiscovered Amerindians visit the West”- implica que su atuendo no oculta, sino que visibiliza la pérdida irrecuperable que es parte de su exilio. ${ }^{13}$ En el texto de Peri Rossi, por lo tanto, se aglutinan múltiples viajes con la siempre inminente posibilidad de naufragio: los viajes de los conquistadores y sus consecuencias, las diferentes migraciones que tuvieron lugar durante el siglo xIx y a principios del siglo xx, y el exilio provocado por la dictadura en Uruguay. Estos múltiples viajes y sus variadas consecuencias son, conjuntamente con "las metáforas que ilustran diásporas y naufragios”, tal como indica Mabel Moraña, un motivo constante tanto en la narrativa como en la poesía de la autora (204). Así aparece en las reflexiones de Peri Rossi:

${ }^{12}$ Esta invención (o lo que son más bien múltiples y paralelas invenciones) permitió, tal como puntualiza Iris M. Zavala, “que los lectores privilegiados de la Corona (y los oyentes) identificaran una serie de verdades como sistema de ficciones (invenciones) útiles para dominar la naturaleza. Que mediante un dominio de la retórica y transposiciones, metáforas y metonimias, se evidencia en la escritura de los conquistadores (desde las cartas de Colón), un afán de inventar para apropiarse del mundo" (2).

${ }_{13}$ Para más información sobre esta instalación, véase: http://www.thing.net/ cocofusco/subpages/ performances/performancepage/subpages/ameridians/ameridians.html. 
Una generación más atrás que la de mis padres, encontramos a los infaltables emigrantes italianos, por ambas ramas. Llegados a América en barcos hacinados, pobres y laboriosos. (No deja de ser irónico que buena parte de sus descendientes, en los años de fascismo latinoamericano, hayamos reemprendido el viaje, en barcos igualmente hacinados, pobres y dejando atrás las raíces). (Deredita 132, citado en Moraña 205)

Esta ironía emerge precisamente de la sensación de una historia repetitiva, de un tiempo cíclico que atrapa a todo sujeto exiliado y termina empapando gran parte de la obra narrativa de Peri Rossi, para culminar, quizá, en aquella nave de los locos que no dejará nunca de navegar. ${ }^{14}$

Debería quedar claro, a la vez, que las travesías y los viajes aquí mencionados no son equivalentes, pero sí son travesías que se cruzan en lo que se refiere a su temática y al espacio. Se trata, después de todo, de viajes que transcurren en el tiempo transhistórico indicado por Julio Ortega. Y el tiempo o concretamente las "cuatro horas, o los cinco mil setecientos setenta minutos" (52) arrebatados a Alicia son los que simbolizan la pérdida y, por extensión, toda pérdida y sacrificio relacionado con el exilio de manera más clara. ${ }^{15}$ En el caso particular de este relato específico, también se trata de una pérdida a la que Alicia en un principio se quiere resistir:

Apartir del cuarto día de navegación, la orden del capitán, transmitida por altavoces, recordaba a los pasajeros que debían adelantar sus relojes treinta minutos. La primera vez, la niña se resistió a la orden. Mantuvo su reloj pulsera en las doce, cuando todo el mundo en el barco corrió la aguja por el circuito de la esfera, con una manera harto frívola de tratar el tiempo, según opinión de Alicia. (51)

Pero Alicia, que madura rápidamente mientras que su padre permanece atrapado en esa infancia postiza y asfixiante, se da cuenta que, pase lo que pase, haga lo que haga, las horas le serán arrebatadas, marcándola y atrapándola en su melancólica condición de exiliada. La pregunta que persiste, la pregunta que también se hace Alicia es ¿qué hacen los tiempo-traficantes con todas las horas robadas?

${ }^{14}$ Olivera-Williams también enfatiza el tiempo cíclico en La nave de los locos: "En un tiempo circular, los espacios repiten, a pesar de su variación, una cadena de tragedias: las injusticias de un sistema jerárquico y arbitrario que permea toda la historia de la cultural occidental” (82).

15 Schmidt también discute la relación entre exilio y tiempo en su análisis del relato, arguyendo que el viaje marítimo se convierte en un "tercer espacio" tanto a nivel de la narrativa, como a nivel de la dimensión psíquica. Todo el pasaje, explica Schmidt, está caracterizado por la pérdida, simbolizado por la pérdida de tiempo en la navegación de este a oeste (225). En un análisis más exhaustivo de lo que ella denomina una “dialéctica del exilio", Sophia McClennen enfatiza la tensión entre diferentes temporalidades (tiempo histórico/tiempo cíclico/tiempo fragmentado) que aparecen en textos en los que se narran diferentes exilios (3). 
¿Qué harán con tantas horas acumuladas? Pensó en barcos llenos de horas robadas, barcos silenciosos que atravesaban el mar con su carga secreta de tiempo. Pensó en barcos fantasmales llenos de hombres que custodiaban los recintos donde el tiempo robado estaba guardado, imaginó traficantes de horas que esperaban a los barcos en puertos sucios, oscuros, comprando horas, las vendían. Pensó en los hombres desesperados que compraban pequeñas cajitas con un tiempo minúsculo, porque los traficantes especulaban con las horas compradas. En un puerto cualquiera, un hombre, ansioso, ve llegar el barco, del barco bajaban una caja azul, y él compra media hora, quizá menos, compra diez minutos robados a tranquilos pasajeros de un barco, a involuntarios emigrantes como su padre y ella, a exiliados. (53)

A estas alturas se podría llegar a otra conclusión fácil y rápida: a pesar de todo, Alicia es una niña, una niña que no es capaz de comprender algo tan sencillo como el cambio de horario a través del Atlántico. Pero Alicia, a pesar de lo que su nombre pueda sugerir, no es una niña, ni siquiera una niña melancólica, sino la representación melancólica de una infancia interrumpida, una infancia, para usar los términos de Olivera-Williams, varada en un naufragio. De manera similar, la obra de Muñiz-Huberman que analizo a continuación mostrará otra representación melancólica de la infancia, también varada, encallada en otro naufragio.

En ambos textos se trata de infancias interrumpidas, naufragadas por el exilio y la pérdida de seres queridos, patrias, objetos, memorias, incluso de tiempo. Son pérdidas que jamás se podrán asimilar completamente, ya que los residuos de las mismas nunca desaparecen, convirtiendo, por lo tanto, a estos dos personajes en encarnaciones de la melancolía.

\section{UNA MEMORIA AGREGADA}

Una respuesta posible a la curiosa pregunta de Alicia es que las minúsculas cajas azules llenas de tiempo robado serán arrojadas al mar al igual que los cuerpos muertos y moribundos que aparecen en el cuadro de Turner; a ese mar que, tal como afirma Alberina en el texto de Muñiz-Huberman, "todo lo engulle” (67). Son horas, por lo tanto, que nunca se recuperarán, horas perdidas en un mar que "limpia implacablemente” (71). Ésa es la conclusión a la que llega la joven Alberina cuando le informan del naufragio del Oropesa, el barco en el que ella y su familia cruzaron el Atlántico rumbo a su exilio mexicano, y que le evoca también la memoria de un hermano muerto a los seis años. El barco, específicamente, naufraga cuando recién estalla la Segunda Guerra Mundial: "El Oropesa ha sido hundido” narra Alberina. “El capitán Dunn ha muerto. Ni un rastro, ni huella, ni un cuerpo vivo” (71).

Al igual que ocurre en el texto de Peri Rossi, se podría argüir que esta novela no es otra cosa que un texto autobiográfico en el que la escritora "transterrada" narra 
su infancia en México. ${ }^{16}$ Pero el subtítulo de Seudomemorias que encabeza el texto ya indica que se trata más bien de un complejo juego que se niega a establecer los límites entre la memoria y la ficción, y que visiblemente cuestiona las divisiones genéricas entre lo autobiográfico y lo ficticio. Castillos en la tierra, tal como indica Luz Elena Zamudio, no trata de "lo que recuerda la narradora, sino de la historia de ese recuerdo, que lleva implícita la idea de una narración-interpretación de los hechos sucedidos” (73). El hecho de que Alberina esté interpretando lo sucedido otra vez la une a la protagonista del texto de Peri Rossi.

Tanto en el cuento de la uruguaya como en la novela de la hispanomexicana se elaboran personajes infantiles que narran las circunstancias de su exilio transatlántico, pero en ningún caso se deberían aceptar como simples voces infantiles que, a causa de una aparente inocencia, nos proveen sus respectivas situaciones con una mirada realista, incluso sincera. ${ }^{17}$ Más bien, en los dos casos, y tal como revela claramente el texto de Muñiz-Huberman, se trata de la construcción de una mirada aparentemente infantil y aparentemente inocente, pero que en el fondo es una representación melancólica de la infancia. En un análisis exhaustivo de este tipo de representación en la obra narrativa de Muñiz-Huberman, Gloria Prado observa que la infancia de los personajes ficticios de la autora casi siempre es "una etapa enormemente dolorosa de la vida” (328). Pero Castillos en la tierra es un texto que oscila entre lo autobiográfico y lo ficticio-son, después de todo, las seudomemorias de la autora- y, tal como apunta Prado, el recuerdo y la representación de esta etapa enormemente dolorosa tiene la función de "poder explicarse a sí misma o, el propio proceso de vida” (328). Así en esta obra híbrida, en la que el recuerdo de esta etapa enormemente dolorosa es "una constante ineludible; presencia grotesca, fantasmagórica, amenazante por lo que fue o por su pérdida” (328), el personaje de Alberina también es algo más complejo que la representación de la memoria de la infancia: es el recuerdo constante de las múltiples pérdidas que involucra cualquier naufragio, como lo evidencian las múltiples reflexiones textuales sobre la memoria:

¿A quién le entregará los recuerdos Alberina? Los recuerdos que ya han sido elaborados y transformados en cuentos maravillosos. Alberina ya no posee una

${ }^{16}$ Uso específicamente la noción de "transtierro" que José Gaos desarrolló en los años cuarenta en México en relación a su propio exilio. Sebastiaan Faber explica que Gaos originalmente creó este neologismo para indicar que su situación en México era mucho más afortunada que la de un desterrado, gracias, sobre todo, a un sentimiento de afinidad política entre el México revolucionario y la República española (214).

17 La construcción del personaje de Alberina se hace obvia con los orígenes del nombre, pues tal como comenta Zamudio no sólo refleja el mismo número de sílabas que Angelina, sino que también es la fusión del nombre de la autora con el de su esposo Alberto (71). 
memoria, sino la historia de una memoria. Una memoria agregada. Una memoria narrada. (50)

Las circunstancias particulares que marcan tanto la vida como la obra de Muñiz-Huberman sugieren a la vez que las capas palimpsésticas que forman las seudomemorias de la autora quizá sean la única manera (o, por lo menos, la manera más efectiva) de narrar los exilios múltiples y entrecruzados que aparecen en obras como las aquí mencionadas, obras en las que los límites disciplinarios o genéricos han perdido gran parte de su validez y de su función.

Las seudomemorias son, por lo tanto, las memorias del recuerdo, el recuerdo del exilio de Alberina y también del exilio de Angelina Muñiz-Huberman, hija de padres españoles refugiados en Francia al estallar la guerra civil. Pero las seudomemorias, o "la historia deAlberina”, que viene a ser lo mismo, no comienzan en México, sino antes, “en Caimito del Guayabal, en la llanura habanera. Y puede que tampoco ahí. Sino aún antes, en tierras lejanas, al otro lado del mar, en alguna playa mediterránea” (49). Alberina aquí narra la historia de las memorias de su familia, el primer exilio en Francia, donde murió su hermano, cuya pérdida y cuya presencia espectral también la acompañarán a largo de todo el texto. ${ }^{18}$ Posteriormente, la familia cruzará el Atlántico para residir en Cuba y finalmente llegar a México en 1942. En la novela, Alberina narra los múltiples exilios que también se materializan a lo largo de la extensa y variada obra de Muñiz-Huberman, y a los que se añade la descendencia cripto-judía de la autora. ${ }^{19}$ Tal como ya han afirmado diversos críticos, se trata de una obra marcada por el exilio y el desarraigo, una obra que se termina convirtiendo en una suerte de espacio propio de la "transterradísima” autora: “Ante la imposibilidad de sentir algún espacio como propio, se refugia en la literatura para construir uno que le pertenezca, a partir de los recuerdos propios y de los ajenos que recibe a través de la tradición oral y escrita” (Zamudio 38).

Pero en Castillos en la tierra, estos mismos refugios a los que se refiere Zamudio también están carcomidos por una memoria traumática: Alberina no sólo cuenta los múltiples exilios de una niña y su familia, sino que la compleja perspectiva de la narradora (representada tanto en primera como en tercera persona) también alude,

\footnotetext{
18 La muerte del hermano también aparece narrada en la novela Tierra adentro (1972).

19 Angelina Muñiz-Huberman supo de la ascendencia sefardí de su familia cuando ya residía en México. Judith Payne explica que se trata de una identificación clandestina, ya que la niña Angelina, al enterarse de la identidad cultural de su familia cuando contaba con sólo seis años, no sólo recibe información sobre la familia de su madre, sino que también recibe un secreto: a causa de la naturaleza velada de la transmisión de esta herencia, Muñiz-Huberman solamente recibió una visión fragmentada y limitada del judaísmo que más tarde pudo suplementar con un estudio más formal del hebreo y de la cábala (Payne 435). Eduardo Mateo Gambarte se refiere al “doble desarraigo” de la exiliada española y judía $(68,72)$.
} 
una y otra vez, a múltiples pérdidas y naufragios que se transforman y recobran nuevos significados.

Las "seudomemorias" son, por lo tanto, memorias que se constituyen entre las brumas de pérdidas y secretos, a la vez que también son las "posmemorias" de la autora, ya que, tal como indica Zamudio, su recuerdo de exilio "está formado, como en la mayoría de los hispanomexicanos, tanto de experiencias vividas en la 'realidad' como de las recibidas a través de los adultos y de la literatura” (42). La obra, por lo tanto, también dialoga con el concepto de "posmemoria" que teoriza Marianne Hirsch en el contexto específico del Holocausto. Dicha "posmemoria", explica Hirsch "caracteriza la experiencia de los que crecen dominados por narrativas que preceden su nacimiento, y cuyas historias propias son vaciadas por las narrativas de las generaciones anteriores, narrativas dominadas por eventos traumáticos que no se pueden ni entender, ni dominar” (22).

En el caso particular de Castillos en la tierra, Alberina no deja que las narrativas anteriores a su nacimiento expulsen las suyas propias. Más bien, el pasado traumático que atormenta a Alberina en su exilio mexicano -la Guerra Civil, la dictadura franquista, el Holocausto y también la Inquisición- aparece una y otra vez en el universo de la niña. Pero, para ella, la memoria de la generación anterior a la suya es más que una pesada carga, es algo que ella roba y arrebata, al igual que los tiempo-traficantes roban las horas a Alicia, a su padre y a otros exiliados y emigrados involuntarios. Así, al soñar con un incendio que en el fondo tuvo lugar durante la infancia de su madre, la niña Alberina

se ha apropiado de esa historia de la madre y es otro pánico sumado a los de la noche. El fuego puede repetirse. Si una chispa del cigarro del padre cae sobre la sábana y abrasa los cuerpos y corre sobre el piso y se sube a la cama de Alberina, Alberina que duerme, muere. (178)

De la misma manera que una travesía siempre es más que una travesía, un naufragio siempre es más que un naufragio en esta obra, tal como lo es en la de Peri Rossi; asimismo, en un texto de una autora tan comprometida con la Inquisición y las huellas sefardíes en España, un incendio también es más que un incendio. Alberina sueña con el incendio que quemó la casa de su madre cuando ésta era niña, pero también sueña con los “fuegos mayores”: “Los fuegos de la Inquisición. Los fuegos del Holocausto” (178). Así, las “seudomemorias” de Alberina no están exactamente dominadas por narrativas anteriores a su nacimiento, como ocurre en el caso de la posmemoria; Alberina justamente fusiona los incendios, los naufragios, las pérdidas, en resumen, los traumas del pasado en sus "seudomemorias".

La infancia de Alberina, por lo tanto, es una infancia interrumpida, náufraga y perdida en el tiempo, una infancia en la que se acumulan tanto las pesadillas 
como la esperanza de la Guerra Civil, el franquismo, pero también de la Segunda Guerra Mundial. Primero es un miedo poco concreto, pero después poco a poco va transformándose en miedo específico a las atrocidades cometidas durante el Holocausto:

En Tamaulipas 185 la torturan en el patio gris. La conducen, junto con otros prisioneros, al piso más alto, y desde ahí, la arrojan por la ventana al empedrado. Su cuerpo cae entre cadáveres. Es obligada a subir, a punta de bayoneta, y es arrojada de nuevo al vacío. Alberina, maltrecha, se finge muerta, pero la descubren y otra vez la lanzan desde lo alto. Así, innumerables veces. Se siente a punto de morir; las vísceras reventadas, los huesos rotos, pero no acaba de morir. (92)

Pero Alberina no sólo tiene pesadillas, y también es aquí donde las posmemorias ya narradas cobran un significado que va más allá de la definición de Hirsch. La niña sueña con un futuro imposible en el que podrá intervenir y cambiar el pasado traumático. Ella sueña con hacerse mayor y, de manera más implícita, con ser hombre para poder regresar a través del Atlántico y a través del tiempo con el fin de intervenir en la historia, transformarla y ganarla. Así, la joven Alberina, al ver triciclos con cubierta de avión en el Parque de la Alameda en la Ciudad de México, piensa que le hubiera gustado aprender a manejar uno y ser aviadora, para hacer "caer a los alemanes y triunfar a los republicanos" (19). Es algo más que un juego de niños: "Le hubiera gustado ir a la guerra, pero aquí, en México, no se pelea. Cuando sea mayor podré ir a la guerra. Las guerras no se acaban. Sus padres sólo hablan de guerras. Podrá escoger a cuál ir. Con esto se contenta” (20). Las referencias a la república perdida que a Alberina le gustaría recuperar abundan a lo largo de todo el texto, fusionando pasado y presente, fusionando también ambas orillas del Atlántico en una travesía perpetua, la misma travesía en la que se roban las horas y cuyo recuerdo Alberina también narra en el texto:

En miniatura y encerrado, el barco es un hotel del que no hay escapatoria. Es una prisión con esparcimientos. Es un punto de reunión y de inevitable encuentro con los demás. Es una comunidad que no puede soslayarse. En el barco se pierden las leyes de la tierra y se crean las leyes del mar: el capitán manda. (66)

El capitán manda, pero su barco, el Oropesa, que transporta a Alberina y a sus padres a su exilio, naufraga llevándose al capitán Dunn y su tripulación al fondo del mar: estamos ante otra descripción de un naufragio. El recuerdo del Oropesa acompañará a la narradora, a la vez que la ausencia de huellas o rastros enfatizan que estas “seudomemorias” están marcadas por múltiples pérdidas que se traducen en un estado melancólico. 
NAUfRAGIO Y MELANCOLÍA

Es importante tener en cuenta, tal como indica Selnes, que el análisis del naufragio como metáfora y a su vez la articulación de la poética de un naufragio no implica quitarle importancia a la realidad de un naufragio y un exilio. Con la yuxtaposición del cuadro de Turner y de la fotografía de Serra, en relación a los textos de Peri Rossi y Muñiz-Huberman se ha enfatizado por lo tanto la conexión entre naufragio, exilio y una noción de pérdida irrecuperable, cuyas huellas espectrales permanecen en las relaciones entre las Américas, España y África que dan forma al Atlántico hispano. Esta pérdida también es una forma de melancolía, condición a la que remite el resto del artículo.

Dentro del discurso freudiano existen dos respuestas posibles a una pérdida y se trata, por supuesto, del duelo y la melancolía. En su ya clásico análisis de ambas, Freud indica que estas condiciones son consecuencia de una pérdida. La melancolía es el resultado de una incapacidad de reinventar y reconstruir el mundo sin el objeto perdido; en otras palabras, es la incapacidad de llevar a cabo el trabajo de duelo, ya que sufrir de melancolía implica la identificación del ego con el objeto perdido. Para Freud, esta identificación significa que el ego incorpora el objeto perdido, engulléndolo igual que el mar que ve Alberina. El lenguaje que utiliza el psicólogo vienés claramente evoca el mismo acto de engullir, ya que Freud explica que el mismo ego no sólo desea incorporar el objeto perdido, sino que incluso lo devora (250). Cristina Moreiras-Menor, cuya noción de lo melancólico también se basa en la obra Black Sun: Depression and Melancholia de Julia Kristeva, enfatiza la manera en que la melancolía ocurre cuando el sujeto es incapaz de asimilar la pérdida y así queda atrapado en un ciclo inacabable: "El sujeto melancólico es incapaz de enfrentarse a la pérdida del objeto y, en consecuencia, lo canibaliza devorándolo y se ensimisma en una perpetua e imposible autocontemplación” (128).

Ahora bien, el psicoanálisis es, como explica Ranjana Khanna, una disciplina masculina y colonialista que promueve la idea de una subjetividad occidental opuesta a un Otro colonizado, femenino y primitivo (ix). En su estudio, por lo tanto, Khanna no usa el psicoanálisis como una herramienta teórica para comprender situaciones, encuentros o discursos coloniales, sino que demuestra cómo las teorías que Freud desarrolló en su momento permitieron la construcción de dichos encuentros, situaciones y discursos. Así, la melancolía pasa a ser algo mucho más complejo que una neurosis que afecta a un individuo específico; el concepto de "melancolía crítica” que Khanna desarrolla se centra en una relación entre el sujeto y la otredad. Al igual que Freud, Khanna comienza diferenciando duelo y melancolía, enfatizando también que en el caso de la melancolía existe un rechazo y a la vez una crítica al sujeto mismo. Llevar a cabo el proceso de duelo significa asimilar la pérdida; sólo 
entonces el ego se podrá reconstituir exitosamente. Khanna también apunta que el duelo puede convertirse en patológico, cuando un objeto perdido conocido no es liberado, sino que el proceso de duelo se convierte en algo constante y termina constituyendo parte de la personalidad de un individuo o un grupo (22).

Conviene detenernos por un momento en esta noción de "duelo patológico", es decir, un proceso de duelo que es interminable y a la vez caracteriza a individuos o grupos específicos. Cualquier reacción a la pérdida que implica un naufragio literal o simbólico también se podría interpretar como un duelo patológico (individual o colectivo) que a la vez podría ser un elemento constitutivo del exilio, incluso de la diáspora. Enfatizo, sin embargo, la melancolía, y no el duelo, en sus conexiones con el naufragio. Para empezar, la nave zozobra y queda rota, igual que el ego que engulle el objeto perdido, $y$, tal como escribe Moreiras-Menor, el sujeto melancólico queda atrapado, varado en el tiempo:

De igual modo que el sujeto se ausenta de sí mismo y del otro, la temporalidad del melancólico está ausentada en la experiencia de un momento vivido como eterno. Sujeto por tanto que se ve enganchado a su experiencia desde una también profunda indiferenciación entre pasado y presente por permanecer en y pertenecer a una memoria sin objeto. (128)

$\mathrm{Al}$ igual que regresar de un naufragio no es posible, el sujeto melancólico no es capaz de rehacer un ego quebrado, ya que no puede asimilar la pérdida del objeto y así lo termina engullendo en su totalidad. Al haber engullido el objeto perdido completamente, éste permanece con el sujeto y así comienza a criticarlo, aunque el sujeto no lo reconoce e ignora qué está criticando. Esto significa que el sujeto se está criticando a sí mismo, pero por cualidades que se asociarían con el objeto perdido (Khanna 22). La autora también enfatiza que incluso en el mismo proceso de duelo un remanente del objeto de duelo siempre permanece al igual que los restos de la nave quebrada en el fondo del mar. La mayoría de las veces no es un resto visible ("ni un rastro, ni una huella, ni un cuerpo vivo" [71] queda del Oropesa, nos recuerda Alberina), pero negar la existencia de este remanente, sugiere Khanna, implicaría "una asimilación imposible y poco ética de la otredad, una negación de la pérdida y de un compromiso con la destrucción que dicha pérdida trajo consigo"(24). Un naufragio, por lo tanto, lleva a este estado melancólico, porque la pérdida irrecuperable permanece en la memoria del sujeto náufrago y esto sólo es posible porque en el caso de la melancolía, y tras la canibalización del objeto perdido, las barreras entre un sujeto y el otro se hacen borrosas, incluso intangibles. La "melancolía crítica" es una respuesta a una pérdida a la que no es posible sobreponerse: las horas robadas a Alicia, la República perdida por la que Alberina desea seguir luchando, los "fuegos mayores" en cuyas cenizas se escribe 
la historia de la familia de Alberina. Esto no quiere decir que ambas protagonistas sufran de melancolía, sino que la relación que establecen con sus propios viajes y exilios es una relación melancólica. Su subjetividad, que a la vez se constituye a través de las múltiples travesías y a pesar de ellas, está anclada, varada en un naufragio del que no es posible regresar. Pero, como ya se indicó al principio de este ensayo, esta imposibilidad no es una inmovilización teórica, sino que es aquí donde se puede comenzar a hablar de lo que sería "el trabajo de la melancolía". Según Khanna:

Mientras que en los escritos de Freud el trabajo de duelo es el trabajo de asimilar el objeto perdido, el trabajo de melancolía tiene una relación crítica con lo perdido y lo enterrado. Se manifiesta a veces en una parálisis, pérdida de movilidad o una incapacidad de diferenciar entre el uso metafórico y el uso literal (demetaphorization) del lenguaje, y así saca a colación un residuo (remainder) que no se puede asimilar. $(25)^{20}$

$\mathrm{Al}$ retomar los textos y los personajes que me sirven para esta reflexión, me enfrento al hecho de que Alberina y Alicia son representaciones de un estado melancólico. Sus travesías transatlánticas se superponen y se encuentran en el ya mencionado "tiempo transhistórico, entrecruzado de relatos una y otra vez actualizados” (Ortega 114). Son también representaciones que nos permiten cuestionar relaciones coloniales, poscoloniales e incluso neocoloniales que enmarcan los flujos transatlánticos pasados y presentes. En ambos textos, y en incontables otros en los que se narran las travesías aquí aludidas, el naufragio aparece "desmetaforizado". Como indica Khanna, la incapacidad de diferenciar entre el uso metafórico y el uso literal del lenguaje es uno de los síntomas de la melancolía, pero es un síntoma a partir del cual se puede iniciar el trabajo sobre una categoría crítica de la melancolía. Se trata de un cuestionamiento radical de las prácticas discursivas que constituyen gran parte de las historias y literaturas latinoamericanas, narradas a partir de los viajes, descubrimientos, sus diversos naufragios y sus múltiples exilios. Dicho cuestionamiento, a la vez, es lo que posibilita o incluso hace necesarios los diversos proyectos que hoy en día se definen como estudios transatlánticos.

Las reflexiones hechas aquí a partir de textos específicos nos remiten a otras travesías trazadas por el coloniaje, la esclavitud, el destierro y la aniquilación, y nos

\footnotetext{
${ }^{20}$ Khanna también deriva su noción de "melancolía crítica" de la obra de los psicoanalistas Nicholas Abraham y Maria Torok, que diferencian entre la "introyección” y la incorporación de un objeto perdido. Mientras que la "introyección" se refiere a la asimilación completa del objeto perdido, es decir, a un proceso continuo, la incorporación se asemeja más al acto de engullir anteriormente mencionado y también implica la fractura de todo significado (24).
} 
permiten abordar otras historias que entrecruzan el Atlántico con el mismo bagaje y la misma persistencia. A partir del exilio que implica una infancia interrumpida, estas dos voces recorren el espacio triangular entre las Américas, Europa y África, revelándolo como una cartografía espectral. Sus voces, como si de las sirenas del mito se tratara, nos alertan al mismo tiempo que nos seducen a inminentes naufragios.

\section{BiBLIOGRAFÍA}

Achugar, Hugo. "Entre dos orillas: Los puentes necesarios”. Represión, exilio y democracia: La cultura uruguaya. Saúl Sosnowski, comp. Montevideo: Ediciones de la Banda Oriental, 1987. 241-47.

Baumgartner, Birgit y Erna Pfeiffer. Aves de paso. Autores latinoamericanos entre exilio y transculturación. Frankfurt y Madrid: Vervuert/Iberoamericana, 2005.

Faber, Sebastiaan. Exile and Cultural Hegemony. Spanish Intellectuals in Mexico, 1993-1975. Nashville: Vanderbilt UP, 2003.

Freud, Sigmund. "Mourning and Melancholia". The Standard Edition of the Complete Psychological Works of Sigmund Freud. J. Strachey, ed. Vol. 14. Londres: Hogarth Press, 1962. 243-58.

Fusco, Coco y Guillermo Gómez Peña. "The Year of the White Bear and Two Undiscovered Amerindians Visit the West. Performance”. Coco Fusco's Virtual Laboratory. 1992-1994. 24 Dec. 2006 <http://www.thing.net/ cocofusco/ subpages/performances/performancepage/subpages/ameridians/ameridians. html>

Gabilondo, Joseba. “Introduction. Special Section: The Hispanic Atlantic”. Arizona Journal of Hispanic Cultural Studies 5 (2001): 91-113.

García Lorca, Federico. "La aurora”. Poeta en Nueva York. Obras Completas. Arturo del Hoyo, ed. Madrid: Aguilar, 1960. 425.

García Márquez, Gabriel. Relato de un náufrago. Buenos Aires: Sudamericana, 2005.

Gilroy, Paul. The Black Atlantic: Modernity and Double-Consciousness. Boston: Harvard UP, 1993.

Gruzinski, Serge. La colonización del imaginario: sociedades indígenas y occidentales en el México español. Siglos XVI-XVII. México: FCE, 1995.

Hirsch, Marianne. Family Frames. Photography, Narrative and Postmemory. Cambridge: Harvard UP, 1997.

Kaminsy, Amy. After Exile: Writing the Latin American Diaspora. Minneapolis y Londres: U of Minnesota P, 1999. 
Khanna, Ranjana. Dark Continents. Psychoanalysis and Colonialism. Durham: Duke UP, 2003.

Kim, Yeon-Soo. The Family Album. Histories, Subjectivities, and Immigration in Contemporary Spanish Culture. Lewisburg: Bucknell UP, 2005.

Mateo Gambarte, Eduardo. "Angelina Muñiz-Huberman: Escritora hispanomexicana”. Cuadernos de Investigación Filológica 18/1-2 (1992): 65-83.

McClennen, Sophia A. The Dialectics of Exile. Nation, Time, Language, and Space in Hispanic Literatures. West Lafayette: Purdue UP, 2004.

Moraña, Mabel. “La nave de los locos de Cristina Peri Rossi”. Texto Crítico 12/3435 (1986): 204-13.

Moreiras-Menor, Cristina. Cultura herida: literatura y cine en la España democrática. Madrid: Ediciones Libertarias, 2002.

Muñiz-Huberman, Angelina. Castillos en la tierra (seudomemorias). México: Hora-actual-Consejo Nacional para la Cultura y las Artes. Ediciones del Equilibrista, 1995.

Naharro-Calderón, José María. El exilio de las Españas de 1939 en las Américas: “¿Adónde fue la canción?” Barcelona: Editorial Anthropos, 1991.

Núñez Cabeza de Vaca, Álvar. Álvar Núñez Cabeza de Vaca: His Account, His Life, and the Expedition of Pánfilo de Narváez. Por Rolena Adorno y Patrick Charles Pautz. 3 vols. Lincoln: U of Nebraska P, 1999.

Olivera-Williams, María Rosa. "La nave de los locos de Cristina Peri Ross”. Revista de crítica literaria latinoamericana 11/23 (1986): 81-9.

Ortega, Julio. "Post-teoría y estudios transatlánticos". Iberoamericana: América Latina, España y Portugal 3/9 (2003): 109-17.

Payne, Judith. "Writing and Reconciling Exile: The Novels of Angelina MuñizHuberman”. Bulletin of Hispanic Studies 74/4 (1997): 431-59.

Peri Rossi, Cristina. "La influencia de Edgar A. Poe en la poesía de Raimundo Arias”. La tarde del dinosaurio. Barcelona: Plaza y Janés, 1980. 43-60. Descripción de un naufragio. Barcelona: Lumen, 1974.

Prado, Gloria. "La vuelta al infierno o la recuperación de la infancia en la obra narrativa de Angelina Muñiz”. Escribir la infancia. Narradoras mexicanas contemporáneas. Nora Pasternac, Ana Rosa Domenella y Luzelena Gutiérrez de Velasco, comp. México: El Colegio de México, 1996. 299-330.

Sánchez Romeralo, Antonio. "El destierro en ideología, el libro de los aforismos de Juan Ramón Jiménez”. El exilio de las Españas de 1939 en las Américas: “¿Adónde fue la canción?”. José María Naharro-Calderón, coord. Barcelona: Editorial Anthropos, 1991. 251-62.

Schmidt, Cynthia. "A Satiric Perspective on the Experience of Exile in the Short Fiction of Cristina Peri Rossi”. The Americas Review 18/3-4 (1990): 21826. 
Selnes, Gisle. "The Metaphoricity of Shipwrecks; or Exile (not) Considered as One of the Fine Arts". Ciberletras 10. Dec. $2003<$ http://www.lehman.cuny. edu/ciberletras/v10/selnes.htm>

Sosnowski, Saúl, comp. Represión, exilio, y democracia: La cultura uruguaya. Montevideo: Ediciones de la Banda Oriental, 1987.

Zamudio, Elena. El exilio de Dulcinea encantada. Angelina Muñiz-Huberman escritora de dos mundos. México: Casa Juan Pablos/UAM Iztapalapa, 2003.

Zavala, Iris M. “'De invenciones': Palabras liminares”. Discursos sobre la "invención de América”. Iris M. Zavala, coord. Amsterdam y Atlanta: Rodopi, 1992. $1-5$. 